\title{
RUNWAY PAVEMENT INSPECTIONS USING DRONE - SAFETY ISSUES AND ASSOCIATED RISKS
}

\author{
Lidija Tomić ${ }^{1}$, Olja Čokorilo ${ }^{2}$, Dragana Macura $^{3}$ \\ 1,2,3 University of Belgrade, Faculty of Transport and Traffic Engineering, Vojvode Stepe 305, 11000 \\ Belgrade, Serbia
}

Received 20 April 2020; accepted 30 June 2020

\begin{abstract}
The increase in drone use over the last few years, as well as a wide range of their applications, has lead to the need to understand and manage safety risks emerging from drone operations, especially in those environments in which drones may influence air traffic in progress. Considering the fact that generally risk represents the effect of uncertainty on objectives, it is important to previously observe possible objective-related effects, that is, to assess the risks which may emerge from the objective being set. The present paper, therefore, aims at identifying, by applying Reason's accident causation model to four different scenarios, possible safety risks of the project of drone application in a runway inspection. Based on the identified risks, and also by using a detailed SWOT analysis, the importance of the implementation of this new drone technology for airports has been demonstrated and defined. The paper ends by suggesting a number of preventive measures which should be implemented in successful risk management.
\end{abstract}

Keywords: aviation, new technologies, drone, airport, risk assessment, safety.

\section{Introduction}

Aviation is a complex system in which changes occur on a daily basis. Nowadays, one of the most important challenges in aviation is synergy between aircraft operations and operations of drones in controlled airspace (Vidović et al., 2019).

Hence, the primary goal of adopting and implementing new measures, technologies, processes in aviation organizations is for the most part for the purpose of increasing safety. Certain measures and technologies are being adopted to increase the safety of specific aircraft operations at the airport such as new drone technology for inspection of contamination on runway pavement. The mentioned technology aims at improving the efficiency and effectiveness of the process, thereby ensuring the necessary conditions of aerodrome surfaces and aircraft operations. However, the application of the mentioned technology in improving one of the processes must be justified in terms of the overall system safety, in this case overall airport safety. It is intuitively clear that when considering the introduction of new measures, technologies and procedures, it is first necessary to consider the risks that those measures, technologies and procedures may involve.

Safety management system by its definition is a systematic approach to managing safety, including the necessary organizational

${ }^{2}$ Corresponding author: o.cokorilo@sf.bg.ac.rs 
structures, accountabilities, policies and procedures (ICAO, 2013a). Moreover, it is a concept that has found wide application in aviation. From an aircraft operations implementation point of view, one of the primary goals is to maintain the level of safety at an acceptable level. This requires, among other things, understanding operational indicators that affect the safety of aircraft operations.

\section{Use of Drones at Airports}

With the development of the drone's technical capabilities, there is a growing range and areas of uses in which the drone is already in use, or is planned to be used in the future. Since the use of drones poses a great hazard to aircraft operations, due to the shared use of airspace, an aspect that is given particular attention is the safety aspect of drone use. Considering the fact that the use of drones is planned in the airspace where a large number of aircraft (such as terminal areas) appears, the tendency to use drones at airports for inspection of contamination of runways represents a huge challenge from a safety perspective.

\subsection{Runway Pavement Inspection}

At airports around the world, inspection of runway surfaces is a daily routine that is performed several times during the day to ensure the adequate condition of those surfaces and safe aircraft operations during take-off, landing, and taxi procedures (Kim et al., 2019).

The number of runway pavement inspections depends on a particular airport, and also on its traffic, but at most airports that number is at least 4 inspections a day. The conventional approach to the inspection of aerodrome surfaces, which is present nowadays at airports, consists of the crossing of aerodrome surfaces by controller with a vehicle, through runways and other roads, who thereby visualize whether there is damage to the surface structure or the presence of foreign objects debris (FOD). The airport's vehicle, which is used for runway inspections, often moves along the runways at high speeds (over $100 \mathrm{~km} / \mathrm{h}$ ), thus creating a possibility of not noticing a foreign object, or the presence of contamination. There are two options for improvement of this process: by increasing the frequency of runways checks or increasing the reliability of FOD detection.

According to the recommendations of the International Civil Aviation Organization (ICAO) and European Union Aviation Safety Agency (EASA), safety assessments are necessary to address safety issues in the case of non-compliance or deviation from regulations, but also before implementing any changes to operations or system's infrastructure.

This paper investigates the risks associated with drone development projects for the purpose of runway inspection at airports worldwide. The idea is to outline the risks that the usage of drones for runway inspections may create, by considering the consequences that those risks may entail, and also by adopting preventative measures which need to be taken with the final goal to reduce risks and negative consequences to the lowest practically level (known in the literature (Čokorilo, 2020; ICAO, 2013b) as ALARP - As Low As Reasonably Practicable).

\subsection{Runway Pavement Inspection using Drone}

One of the benefits of drone usage for pavement condition inspections include availability of high-resolution photographs that can be documented (Airsight, 2019). 
This provides an opportunity to improve many of the existing runway contamination activities and procedures. Inspections of airport surfaces by using drone are very effective, but they require careful planning of each of the following steps:

- Definition of the area to be inspected;

- On-site drone inspections;

- Image post-processing;

- Analysis and documentation.

The idea of this innovative method is that there is an operational centre behind the drone operations, with technical support, from which controller operates the drone, and also communicates with the necessary services: Air Traffic Control, airport services, etc. Technical support also monitors video record from drone cameras on the appropriate screens and, if necessary, stops the drone at specific parts of the runway to identify the presence of contamination on the surface.

\section{Collision between Drone and Aircraft at Airports - Reason's Model of Accident Causation}

It is widely acknowledged that accidents in complex systems occur owing to the concatenation of multiple factors, where each may be necessary but where they are only jointly sufficient to result in an accident. Complex systems contain such potentially multi-causal conditions, but only rarely do they arise thereby creating a possible trajectory for an accident. These vulnerabilities are often "latent". Furthermore, most of them are a product of the organization itself, as a result of its design (e.g. staffing, training policy, communication patterns) or as a result of decisions made by managers (EUROCONTROL, 2006).

(Reason, 2016) provided crucial contribution to the concretization of this idea by proposing a model of how accidents could be seen as the result of interrelations between real time unsafe acts by front line operators and latent conditions.

The idea of accidents due to the inadequate organization, which Reason's model is essentially based on, can be understood through the "block building approach", which consists of five building blocks as shown in Fig. 1 (ICAO, 2009).

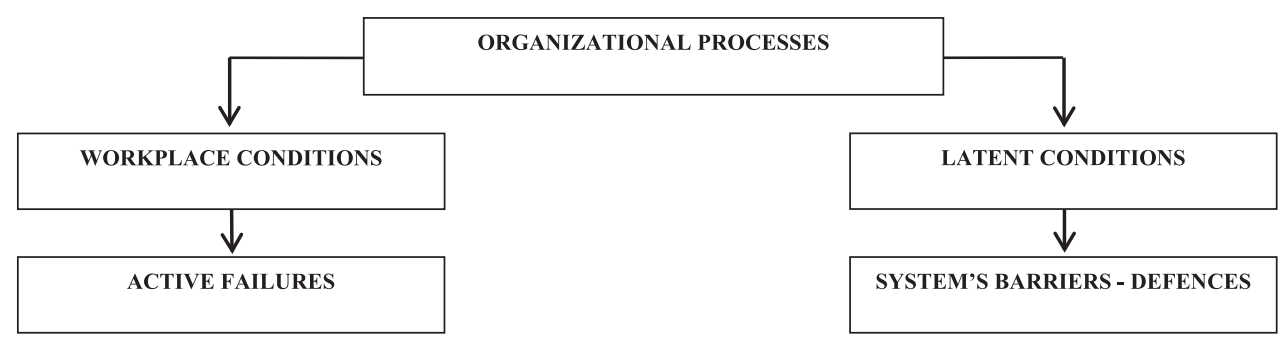

Fig. 1.

James Reason's Model of Accident Causation

For the purpose of this paper, four possible scenarios were developed to determine the safety risks that lead to the unsafe state of the system and/or lead to a crash between aircraft and drones used to inspect runway contamination. Four scenarios, on which Reason's model were applied, are as follows: - Ingesting of drone by aircraft engine; 
- Collision of drone with aircraft 's windshield;

- Collision of drone with trailing/ leading edge of aircraft wing;

- Collision of drone with aircraft 's landing gear.

Generally, the severity of the collision between drone and aircraft, mentioned in the previous four scenarios, depends on the specific circumstances: the size and weight of the drone being used at a particular airport, the speed of the drone and aircraft during the collision, the collision point, as well as the type of aircraft involved in the collision. Table 1 contains the "blocks" previously mentioned which explain the accident occurrence for defined scenarios, and the data in the table are based on personal views on organizational processes, working conditions, latent conditions, active failures, and system's barriers.

\section{Table 1}

James Reason's Accident Causal Model - Application on Collision Between Drone and Aircraft

\begin{tabular}{|c|c|}
\hline \multicolumn{2}{|c|}{$\begin{array}{l}\text { Organizational Processes } \\
\text { Activities over which any organization has a reasonable degree of direct control }\end{array}$} \\
\hline \multicolumn{2}{|c|}{ Non-compliance with international regulations in the field of drone application at airports } \\
\hline \multicolumn{2}{|c|}{ Aircraft certification standards relating to the resistance of a structure on drone impacts } \\
\hline \multicolumn{2}{|c|}{ Training program for drone operators and other participants } \\
\hline \multicolumn{2}{|c|}{ Absence of universal flight routes for drone movement during inspection of runways } \\
\hline Working Conditions & Latent Condition \\
\hline $\begin{array}{l}\text { Factors that directly influence the efficiency of people in } \\
\text { aviation workplaces }\end{array}$ & $\begin{array}{c}\text { Conditions present in the system before the accident, } \\
\text { made evident by triggering factors }\end{array}$ \\
\hline Inspections of runways between close flights & High traffic volume per unit of time \\
\hline $\begin{array}{l}\text { It is only possible to visual control drone } \\
\text { locations during inspection }\end{array}$ & $\begin{array}{c}\text { Pressure to drones operators to move drone as } \\
\text { soon as possible from the active runway }\end{array}$ \\
\hline $\begin{array}{l}\text { Physical distance between drone and drone } \\
\text { operator }\end{array}$ & $\begin{array}{l}\text { Emergency situations (return of aircraft } \\
\text { after take-off at the airport due to bird strike, } \\
\text { technical malfunction of aircraft, etc.) in which } \\
\text { drone must quickly remove from the runway }\end{array}$ \\
\hline $\begin{array}{c}\text { Inspections in complex meteorological } \\
\text { conditions }\end{array}$ & Other drones at the airport \\
\hline $\begin{array}{c}\text { Active Failures } \\
\text { Actions or inactions by people (pilots, controllers, } \\
\text { maintenance engineers, aerodrome staff, etc.) that have an } \\
\text { immediate adverse effect }\end{array}$ & $\begin{array}{l}\text { System's Barriers - Defences } \\
\text { Resources to protect against the risks that organizations } \\
\text { involved in production activities must confront }\end{array}$ \\
\hline $\begin{array}{l}\text { Drone operator errors while reporting actual drone } \\
\text { position to air traffic controller (ATCo) }\end{array}$ & The drone operator must have a proper license \\
\hline $\begin{array}{l}\text { Loss of control of the drone and/or interruption of } \\
\text { image }\end{array}$ & $\begin{array}{c}\text { Establishing communication between drone operator } \\
\text { and ATCo }\end{array}$ \\
\hline $\begin{array}{l}\text { ATCo errors while issuing clearance to enter active } \\
\text { runway at complex airport design }\end{array}$ & $\begin{array}{c}\text { Compliance with recommendations issued by } \\
\text { aviation organizations related to drone weight that } \\
\text { may be used for inspections }\end{array}$ \\
\hline $\begin{array}{l}\text { Runway incursion of aircraft during runway } \\
\text { inspection due to pilot or ATCo error }\end{array}$ & Limited airport space in which drones can operate \\
\hline
\end{tabular}


The situation is more complex for airport design that includes a system of multiple runways, i.e. at airports where the number of runways requires increasing the number of drones participating in the inspections, which creates new safety risks, but this time between active drones.

The consequences of the four scenarios listed above are different, first of all regarding severity and damage they may cause, but also regarding the processes, operating conditions, and system failures (listed in the previous table), which are common to all four scenarios. If, based on the Reason's model, one wants to evaluate the risks that drone use causes, he has to highlight the consequences of the scenario first (Table 2 ), and only then include the likelihood of certain events which depends on the airport using drone for runway inspection.

Table 2

Consequences of Four Scenarios of Drone-aircraft Conflict

\begin{tabular}{|c|c|c|}
\hline Scenario No. & Scenario & Consequences \\
\hline 1 & Ingesting of drone by aircraft engine & $\begin{array}{c}\text { Loss of engine thrust; Damage to engine } \\
\text { compressor and turbine elements; Engine fire; } \\
\text { Destruction of the drone. }\end{array}$ \\
\hline 2 & Collision of drone with aircraft's windshield & $\begin{array}{c}\text { Windshield crack; Decrease visibility from } \\
\text { the cockpit; Injury to captain and first officer; } \\
\text { Damage or destruction of the drone. }\end{array}$ \\
\hline 3 & Collision of drone with aircraft's landing gear \\
aircraft wing & $\begin{array}{c}\text { Impaired structural integrity - influence on the } \\
\text { creation of lift; Fire if drone breaks wing and fuel } \\
\text { tanks in it; Damage or destruction of the drone. }\end{array}$ \\
$\begin{array}{c}\text { Damage of the tire of the main landing gear; } \\
\text { Damage of parts on the structure of the braking } \\
\text { system; Damage or destruction of the drone. }\end{array}$ \\
\hline
\end{tabular}

After determining the severity of the consequences and the likelihood of a collision, which in this particular case depends on the volume of traffic and the planned intensity of inspection at a particular airport, it is possible to perform a risk assessment, which is most often done using a risk matrix (Čokorilo and Miščević, 2018). An example of a risk assessment matrix is given below (Table 3).

\section{Table 3}

Risk Assessment Matrix

\begin{tabular}{|c|c|c|c|c|c|}
\hline $\begin{array}{c}\text { Collision between } \\
\text { Drone and Aircraft }\end{array}$ & \multicolumn{5}{|c|}{ Risk Probability } \\
\hline Risk Severity & Frequent & Occasional & Remote & Improbable & $\begin{array}{c}\text { Extremely } \\
\text { Improbable }\end{array}$ \\
\hline Catastrophic & 3 & 3 & 3 & 2 & 2 \\
\hline Hazardous & 3 & 3 & 3 & 2 & 1 \\
\hline Major & 3 & 3 & 2 & 1 & 1 \\
\hline Minor & 2 & 1 & 1 & 1 & 1 \\
\hline Negligible & 1 & 2 & 1 & 1 \\
\hline
\end{tabular}


The idea of the matrix, and the three levels of risk defined in it (where red represents the highest level of risk, yellow moderate and green the lowest level of risk), is to provide the "guidelines" for matrix users to determine, after assessing the level of risk, how worrying this risk for organization is and which measures need to be taken.

\section{What are the Benefits for Airports of using Drones for Runway Inspection?}

Opinions on the drone usage for runway inspection differ among the authors who have addressed this issue. For instance, (Likar et al., 2016) in their paper state that the use of a drone for these purposes does not provide much benefit to the airport because of the low speeds that drones can achieve relative to the speeds developed by a vehicle used at the airport for this type of checks. However, the development of the drone's technical capabilities is being expanded and the speeds that drone can achieve now, after a few years since the mentioned research, are actually equal, even higher, than those of airport vehicles used for airport runway inspections.

\subsection{SWOT Analysis}

Based on the risks recognized using the Reason's model, the Table 4 presents a SWOT analysis based on the benefits from drone usage in inspecting the runway contamination for airports.

\section{Table 4}

SWOT Analysis of Drone usage for Airport's Runway Inspections

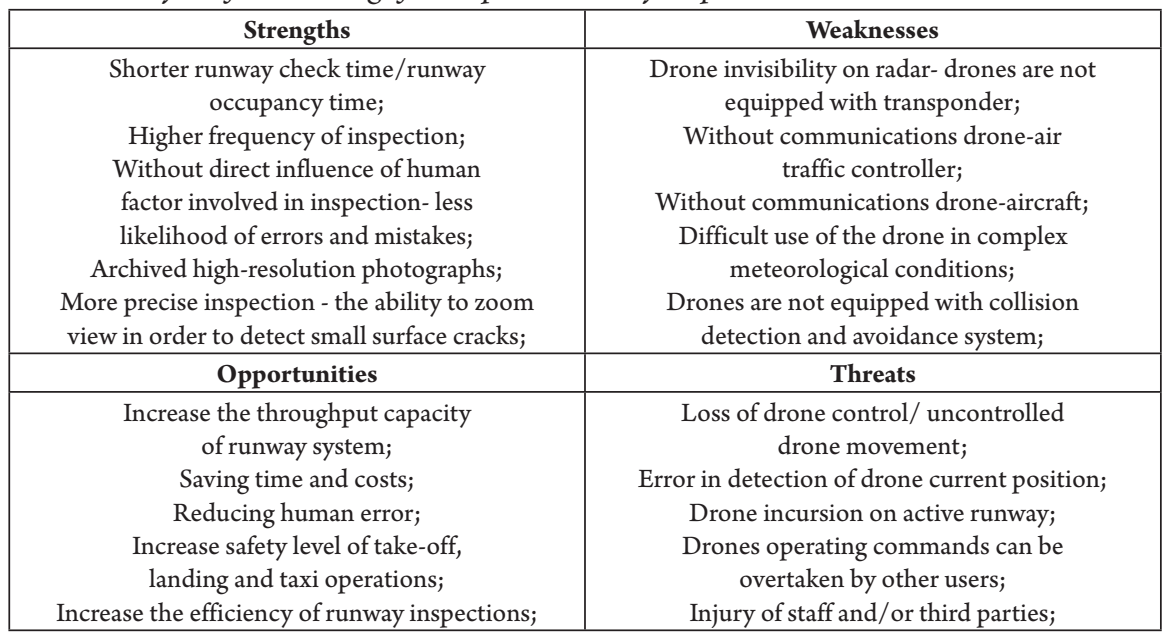

\section{Preventative Measures and Future Research}

As noted in the introduction, in aviation operations, Safety Management System (SMS) should be risk-based, and has to carefully review possible risks in the observed system, with the final aim of weighing up whether we have taken enough precautions, or should we do more to prevent possible harm (Elkhweldi and Elmabrouk, 2015). The ability to detect the incipient indicators and the collective's will to implement wide ranging corrective measures are essential prerequisites 
for an effective risk management programme (Reason et al., 2001).

Based on the risks identified by the Reason's model, as well as the weaknesses and threats using the SWOT analysis, Table 5 proposes measures that should be taken so as to act proactively and prevent the risks from having a negative impact on the observed system.

\section{Table 5}

Proposed Measures

\begin{tabular}{|c|c|}
\hline Measure No. & Measure Description \\
\hline 1 & Equip drone with transponder to be visible on the radar. \\
\hline 2 & Equip drone with airborne conflict detection and resolution device (such as Traffic Colision \\
Avoidance System - TCAS).
\end{tabular}

The proposed measures are mostly related to defining operational requirements at the regulatory level, but there are equally important systems procedures for risk detection and control, which are achievable through the adoption of appropriate systems barriers- various technological solutions, such as: the introduction of transponders on drones so that they can be visible on the radar; the creation of a database of flight plans containing the planned drone movement paths in order to separate them from other traffic at a given airport (from aircraft operations).

Regarding the future related research, it is first necessary to apply developed measures to a specific traffic pattern in order to examine whether they are adequate and whether they should be supplemented or replaced by other better solutions to the addressed risks.

\section{Conclusions}

Accidents caused by inadequate organizational processes are a product of recent times or, more specifically, a product of technological innovations which have radically altered the relationship between systems and people. Any change in a complex system, such as the aviation system, including the introduction of new technologies, initially 
requires safety assessment of the risks that this change or innovation may create. The use of a drone at an airport for inspection of runway contamination has many benefits that are first reflected in increasing the capacity of the runway system and increasing the safety of aircraft operations through a higher frequency of daily runway check that can be done by drones, but also in reducing costs, reducing human error, etc. However, there are also weaknesses and threats to the system such as drone invisibility on the radar, loss of drone control, lack of direct communication between drone and Air traffic control, difficult use in complex meteorological conditions, and other "deficiencies" that could ultimately lead to a collision between aircraft and drone. Weaknesses and threats must be constantly monitored and controlled in order to minimize the risks before they deploy a negative impact on the aviation safety.

\section{References}

Airsight. 2019. Runway pavement inspections using airsight drone. Available from internet: <https:// www.airsight.de/projects/item/runway-pavementinspections-using-airsight-drone/>.

Čokorilo, O. 2020. Aircraft Safety [In Serbian: Bezbednost vazduhoplova]. University of Belgrade, Faculty of Transport and Traffic Engineering, Belgrade, Serbia.

Čokorilo, O.; Miščević, M. 2018. Civil Drones: Safety Issues. In Proceedings of the International symposium: Strategical transport development in Southeast Europe. Budva, Montenegro, 107-113.

Elkhweldi, M.A.; Elmabrouk, S.K. 2015. Aviation risk management strategies: Case study. In Proceedings od the 2015 International Conference on Industrial Engineering and Operations Management (IEOM). IEEE Dubai, UAE, 636-642.
EUROCONTROL. 2006. Revisiting the "Swiss cheese" model of accidents. EUROCONTROL, Brussels. 35 p. Available from internet: <https://www.eurocontrol.int/ eec/public/standard_page/DOC_Report_2006_017. html>.

ICAO. 2009. Safety Management Manual. Second edition. International Civil Aviation Organization, Montreal, Canada. 264 p.

ICAO. 2013a. ICAO Annex 19 - Safety Management. International Civil Aviation Organization, Montreal, Canada. 44 p.

ICAO. 2013b. Safety Management Manual. Third edition. International Civil Aviation Organization, Montreal, Canada. 251 p.

Kim, S.; Paes, D.; Lee, K.; Irizarry, J.; Johnson, E.N. 2019. UAS-based airport maintenance inspections: Lessons learned from pilot study implementation. In Computing in Civil Engineering 2019: Smart Cities, Sustainability, and Resilience. Reston, VA, American Society of Civil Engineers, 382-389.

Likar, P.; Hulek, D.; Lalis, A. 2016. Use of remotely piloted aircraft systems in airport operations, Acta Avionica 18(2): 1-6.

Reason, J. 2016. Managing the risks of organizational accidents. Routledge, USA.

Reason, J.T.; Carthey, J.; De Leval, M R. 2001. Diagnosing "vulnerable system syndrome": an essential prerequisite to effective risk management, BMJ Quality \& Safety 10 (Suppl 2): ii21-ii25.

Vidović, A.; Mihetec, T.; Wang, B.; Štimac, I. 2019. Operations of Drones in Controlled Airspace in Europe, International Journal for Traffic and Transport Engineering 9(1): 38 - 52 . 